\title{
ТОПОНИМИЧЕСКОЕ ПРОСТРАНСТВО МОКША-МОРДОВСКОГО СЕЛА СТАРАЯ БИНАРАДКА САМАРСКОЙ ОБЛАСТИ
}

\section{TOPONYMIC AREA OF THE MOKSHA-MORDOVIAN VILLAGE} "STARAYA BINARADKA", SAMARA REGION

N. Belenov

Summary: The article introduces into scientific circulation and analyzes the toponymic nomenclature of the Moksha-Mordovian village of Staraya Binaradka in the Krasnoyarsk region of the Samara region and its environs. Other elements of the toponymic space of the Staraya Binaradka are also involved in the analysis - the corpus of geographical vocabulary of the starobinaradsky dialect of the Moksha-Mordovian language and the toponymic traditions that exist among the population of this village. The main source of materials for the article was the data of the author's field research conducted during the 2018-2020 seasons.

Keywords: toponymy, toponymic area, Mordva, Moksha-Mordovian language, Staraya Binaradka, Samara region.

\section{Введение}

$\mathrm{B}$ первые в официальных источниках село Старая Бинарадка упоминается в 1747 г., в материалах второй ревизии [РГАДА, ф. 350, оп. 2, ч. 2, д. 3351]. Учитывая сведения о жителях села, для большинства из которых указываются прежние места проживания по данным первой ревизии (1719-1727 гг.), а также ряд архивных документов по истории мордвы с. Бахилово, расположенного на Самарской Луке [6, 7], можно полагать, что Старая Бинарадка возникла незадолго до второй ревизии. Территория, на которой она была основана, несколько столетий до этого входила в зону хозяйственного освоения бахиловской мордвы, проживавшей на Самарской Луке и имевшей здесь покосы и бортные ухожаи. В доказательство владения ухожаями бахиловцы предъявляли жалованную грамоту казанского хана Сафая 6858 г., которая до настоящего времени не сохранилась, а сама информация о ней, встречающаяся у Г.И. Перетятковича (без указания даты) [16] и А.А. Гераклитова $[6,9]$, содержит ряд неточностей. Главная из них - дата документа, указывающая на середину XIV в., когда самостоятельное Казанское ханство еще не существовало. Впрочем, под казанским ханом Сафаем можно понимать не Сафа-гирея, как это делает Г.И. Перетяткович [16], а представителя более ранней ханской династии. Известно, что ряд улусов имели своих правителей (официальный титул - улусбеки, для правителей рангом ниже - темники), которые могли именоваться ханами, в

\author{
Беленов Николай Валерьевич \\ К.п.н., дочент, Самарский государственный сочиально- \\ педагогический университет \\ belenov82@gmail.com
}

Аннотация: В статье вводится в научный оборот и анализируется топонимическая номенклатура мокша-мордовского села Старая Бинарадка Красноярского района Самарской области и его окрестностей. К анализу привлекаются также другие элементы топонимического пространства Старой Бинарадки - корпус географической лексики старобинарадского говора мокша-мордовского языка и бытующие у населения данного села топонимические предания. Основным источником материалов для статьи послужили данные полевых исследований автора, проводившихся на протяжении сезонов 2018-2020 гг.

Ключевые слова: топонимика, топонимическое пространство, мордва, мокша-мордовский язык, Старая Бинарадка, Самарская область.

особенности у соседних народов еще в составе Орды, и обладать некоторой самостоятельностью [11, 245]. По-видимому, грамота действительно существовала, поскольку использовалась жителями Бахилова в качестве доказательства прав на ухожай. Более того, А.А. Гераклитов полагает, что оброчная грамота 1599/1600 г., данная бахиловской мордве Борисом Годуновым, являлась подтверждением этого документа $[6,9]$.

Именно выходцы из Бахилова образовали основу мокша-мордовского населения Старой Бинарадки, что подтверждается и материалами второй ревизии.

\section{Обзор литературы}

Топонимия мордвы эпизодически освещалась в работах по этнографии и краеведению еще в императорской России [12], однако предметом специального исследования данное направление становится уже в советское время, в послевоенный период. Одной из первых работ такого рода можно считать обстоятельную статью А.И. Попова [17]. В дальнейшем общие и частные вопросы мордовской топонимии получили развитие в трудах ученых-филологов Мордовской АССР, в том числе в фундаментальных словарях [9; 20]. В настоящее время исследования мордовской топонимии Республики Мордовия и других территорий проживания мордвы продолжаются [7; 8].

Для топонимии мордвы Заволжья главной (и, по су- 
ществу, единственной специальной) работой является статья ведущего специалиста по мордовским языкам Д.В. Цыганкина «Ойконимия мордовского Заволжья» [19]. Некоторые вопросы мордовской топонимии данных территорий рассматривались также в обзорных работах по топонимии региона $[1 ; 2]$.

Географическая лексика старобинарадского говора мокша-мордовского языка была подробно проанализирована нами в специальной статье [3].

\section{Материалы и методы}

Основными материалами настоящего исследования послужили сведения по топонимике с. Старая Бинарадка и его окрестностей, а также по географической лексике старобинарадского говора мокша-мордовского языка, собранные автором на протяжении полевых сезонов 2018 - 2020 гг.

Методы нашего исследования обусловлены его целью и задачами. При фиксации элементов топонимического пространства с. Старая Бинарадка мы опирались на форму, разработанную специально для финно-угорских языков Г.М. Кертом [10].

\section{Географические названия с. Старая Бинарахка и его окрестностей}

\section{Баба 032}

Название пруда в Старой Бинарадке, по ряду свидетельств, организованного на месте естественного озера. Рассматриваемый лимноним происходит из мокша-мордовского языка; по словам местных жителей, название озера переводится как 'баба плачет'. Нам данное название было объяснено информантами тем фактом, что ранее около пруда совершались моления о дожде. В старобинарадском говоре глагол озамс не употребляется в значении 'плакать', он здесь, как и в литературно-письменном мокша-мордовском языке, имеет значение 'молиться'. Учитывая местные предания о совершении на озере молений, можно предположить, что элемент озг в названии озера восходит к общемордовскому озкс $(m)$ 'моление (моления)', а ассоциации с плачем, вероятно, возникли ввиду специфики мордовских языческих ритуалов уже в среде обрусевшей мордвы.

История термина озк представляется достаточно сложной. Так, П.И. Мельников-Печерский считает, что изначально слово озк у мокшан и озаис у эрзян и терюхан означало мелкого духа, который рождается из искр, высекаемых высшими существами [14]. Если эти существа в мордовском пантеоне воспринимались как добрые, то и духи, высеченные ими, были добрыми, и наоборот. При этом сам автор утверждает, что уже к середине XIX в. данные термины приобретают также значение 'моление'.

В. И. Вершинин для лексемы озкс дает лишь одно значение - 'языческое моление' с производными от него глаголом озондомс'молиться' и титулом жреца у эрзян озатя. Исследователь предполагает связь данного термина с общемордовским глаголом азомс 'сказать' и со словом азкс 'рассказ'. Также он приводит марийские параллели [5: 310].

Х. Паасонен указывает следующие значения для термина Osks-ozks: 'жертва', ‘праздник жертвоприношения', 'моление,' 'общее жертвенное моление'. Он же отмечает употребление термина в теонимах, например: Osks-lej sarko-paz'Властелин жертвенной долины' [21: Т.3: 1397].

В наиболее раннем списке мордовских слов, дошедшем до нас в сочинении Н. Витсена «Северная и Восточная Тартария», также имеется материал по рассматриваемой лексеме [22]. Сведения, представленные Н. Витсеном, относятся ко второй половине XVII в. и, насколько можно судить, являются списком слов, записанных у носителей одного из мокшанских говоров (впрочем, в виде исключения встречаются и эрзянские лексемы, например (neved). Подробный анализ памятника с точки зрения его диалектной принадлежности выполнен А.П. Феоктистовым [18]. В данном списке значится и глагол молиться, который передан как Osndadaschkaindi. Здесь первая часть слова osnda, вероятно, является передачей мокшанского глагола озондомс, а вторая schkaindi означает 'Богу' (от мокшанского Шкай 'Бог' и -нди - мокшанский суффикс дательного падежа).

Названия водных объектов (озер, прудов, родников) с подобного рода семантикой, связанной с различными ритуалами, имеют у мордвы достаточно широкое распространение. Например, в Борском районе в окрестностях с. Коноваловка нами отмечен колодец Бабань лисьма [ПМА, Самарская область, Борский район, Коноваловка, 2019], а в Клявлинском - более редкий вариант Цёра лисьма 'Родник парней' [ПМА, Самарская область, Клявлинский район, Старый Маклауш, 2019]. П.И. Мельников-Печерский в этнографической работе о мордве специально разъяснял в примечаниях, что слово баба у мордвы означает не женщину вообще, а только вдову [14]. По нашим наблюдениям, в настоящее время баба у мордвы скорее означает не 'женщина' и не 'вдова', а 'старуха', что, учитывая ведущую роль пожилых женщин в сохранении языческих обрядов у мокшан и эрзян, семантически оправдано. У.Х. Паасонена также отмечены значения 'старуха; старая женщина' [21: Т.1: 63]. Семантический переход от значения 'вдова' к значению 'старуха' тоже представляется вероятным.

\section{Банаровка}

Название одной из улиц в Старой Бинарадке. Со слов 
информантов: «Банаровка - так называется улица за мостом. Это из-за того, что там Барановы жили. А в разговоре потом постепенно из Барановки в Банаровку превратилось» [ПМА, Самарская область, Красноярский район, Старая Бинарадка, 2019]. Подобный мотив в названиях улиц (от фамилии или уличного прозвища проживавших) распространен в Старой Бинарадке, как и в других мордовских селах региона.

\section{Буйлань просек}

Название дороги в бору у Старой Бинарадки. По словам информаторов, происхождение названия неизвестно [ПМА, Там же, 2019]. По-видимому, нельзя исключать антропонимную основу в топониме: Буйла - антропоним + -нь - аффикс принадлежности в мордовских языках + просек 'лесная дорога', 'дорога вообще' = 'дорога Буйлы'. Учитывая наличие в данном топонимическом пространстве названия Молгачёвский просек, указывающего на направление соответствующей дороги к с. Молгачи, нельзя исключать указательную мотивацию топонима и в данном случае. Из расположенных в окрестностях Старой Бинарадки населенных пунктов фонетически допустимо возводить основу Буйла к ойкониму Буян, однако, надо отметить, что название Буян старобинарадцам хорошо известно, и оно ими никак не искажается.

\section{Бульмагай}

Название одного из прудов в Старой Бинарадке. Со слов информантов: «Озеро там, речка. Рассказывают, привезли туда колокол, зарыли в землю. А он бил все равно, тогда забили кошмой колокол» [ПМА, Там же, 2019]. Приведенные сведения относятся к попыткам объяснить деэтимологизированный ныне в старобинарадском говоре мокша-мордовского языка топоним. По-видимому, в первую очередь внимание «народной топонимики» сконцентрировано на форманте -гай, который, судя по неоднократному упоминанию в легенде колокола и его звона, восходит к мокша-мордовской лексеме гайнямс 'звучать; звенеть'. Основа бульма может представлять собой фонетико-морфологически адаптированный в мокша-мордовской этноязыковой среде тюркский гидронимический термин с основой була/булак 'источник; исток', с вероятным добавлением мордовского аффикса общности -ма. Во всяком случае, большинство подобных названий с территории Республики Мордовия этимологизируются Д.В. Цыганкиным именно так [20]. Формант -гай в данном случае действительно может восходить к лексеме гайнямс, если естественные процессы на дне озера приводят к выделению газов на его поверхности, что также находит параллели в мордовской лимнонимии.

\section{Bepe куре}

Название возвышенной части с. Старая Бинарадка. В топонимической номенклатуре эрзянских сел данному элементу обычно соответствует элемент топонимического пространства Вере пе [4]. Семантика данных устойчивых словосочетаний практически идентична, при этом если рассматривать их дословный перевод, то точнее номинируемые объекты отражает словосочетание вере куре 'верхняя часть села', нежели вере пе 'верхний конец'. Термин куре в старобинарадском говоре означает 'небольшое село - меньшее, чем обозначаемое термином веле'. Наиболее удачным считаем предложенный для него Д.В. Цыганкиным перевод 'слобода'- в том значении, который данный термин приобрел в XX в. [20: 331].

\section{Винарад}

Местное название р. Бинарадки, протекающей через село. В старобинарадском говоре термин винарад имеет значения: 'река' и 'ручей' [ПМА, Там же, 2019]. Надо отметить, что термин ляй/лей для обозначения рек в рассматриваемом говоре неизвестен совершенно, ни в одном из значений, аналогично мокша-мордовским говорам Самарской Луки (исключение составляет бахиловский говор, однако там велика вероятность позднего заимствования от эрзянских переселенцев) [4]. Вопрос о том, является ли термин винарад самостоятельным, либо он стал производным от названия реки, остается открытым. Мы на основе его этимологизации склоняемся к первому варианту.

\section{Калма лотка дол}

Название места, где располагается сельское кладбище. Со слов информаторов: «Калма лотка дол - это где старое кладбище, в селе. Новое - в лесу» [ПМА, Там же, 2019]. Название является гибридным, русско-мордовским: калма 'могила', 'кладбище' + лотка 'овраг' + дол заимствованный из русского языка термин, бытующий в старобинарадском говоре в значении 'пологий овраг' = 'кладбищенский пологий овраг'.

\section{Колбас поле}

Название одного из полей в окрестностях Старой Бинарадки. Со слов информаторов: «Так называется поле потому, что форма у него удлиненная и закругленная с концов» [ПМА, Там же, 2019]. Обращает на себя внимание использование в топониме русского термина поле при мордовской грамматической структуре. Именование полей по их форме широко распространено в мордовской топонимии, подтверждающие примеры имеются и в окрестностях Старой Бинарадки.

\section{Мазы поле}

Название одного из полей в окрестностях села. Топоним является гибридным, русско-мордовским: мазы 
'красивый' + поле - заимствование из русского языка, в старобинарадской топонимии повсеместно используется вместо собственно мордовской лексемы паксе (вариант литературно-письменной лексемы пакся в старобинарадском и самаролукских говорах мокшамордовского языка) = 'красивое поле'. Топоним имеет множество семантических параллелей в мордовских говорах Самарского Поволжья, обычно в форме мазы луга. Лимнонимические параллели с территории Самарской Луки остаются под вопросом в связи с неочевидностью этимологии последних [4].

\section{Орёлонь овраг}

Название одного из оврагов в окрестностях села. Топоним примечателен тем, что, состоя из русских лексем, имеет мордовское грамматическое оформление: орёл орнитоним +-нь - мордовский аффикс принадлежности + овраг = 'орлов овраг'. Форма топонима в данном случае исключает возможность возведения его к антропониму Орлов, что подтверждают и сообщения информантов, объясняющих данное название объекта тем, что он служил местом гнездования орлов [ПМА, Там же, 2019] (под которыми можно понимать любых крупных хищных птиц). При этом в Самарской области также известно несколько видов настоящих орлов.

\section{Песок нанго}

Название части с. Старая Бинарадка. Объяснение топонима со слов информантов: «У нас половина села на песке стоит, до клуба - улица Садовая. А от церкви - там чернозем уже идет» [ПМА, Там же, 2019]. По-видимому, элемент нанго играет в старобинарадском говоре ту же роль, что и послелог ланга/ланго в литературно-письменных мордовских языках, а лексема шувар/чувар заменена русским заимствованием песок во всех без исключения мордовских говорах Самарского Поволжья (но сохраняется в ряде эрзянских говоров региона в форме човар со значением 'ступка'). Послелог нанго бытует, выполняя ту же роль, и в близкородственном для старобинарадского молгачевском говоре мокша-мордовского языка [ПМА, Самарская область, Красноярский район, Молгачи, 2020]. Кроме того, наличие близкого послелога - напкс - фиксируется в шокшинском диалекте [15]. Итак, название данной части села имеет значение 'на песке'.

\section{Пuче ne}

Название одной из частей с. Старая Бинарадка. Объяснение топонима со слов информантов: «Пиче пе - это в начале села у нас, Сосновый конец. До семидесятых годов там проходил карнавал школьный» [ПМА, Самарская область, Красноярский район, Старая Бинарадка, 2019]. С мокша-мордовского языка на русский язык топоним переводится следующим образом: пиче 'сосна' + ne 'конец' = 'сосновый конец'. Старая Бинарадка расположена на окраине большого соснового бора, который является одним из останцев лесного массива, ранее располагавшегося на левобережье Волги между устьями рек Сок и Большой Черемшан и в XVII в. носившего название «Большой бор» [6]. В районе села под названием Песок нанго сосны растут непосредственно на территории Старой Бинарадки, поэтому соответствующая часть данного района носит название Пиче пе.

\section{Сабань поле}

Название одного из полей в окрестностях села. Объяснение топонима со слов информантов: «Это поле такое, если по-русски, то Плуговое. Пахали там, наверное» [ПМА, Самарская область, Красноярский район, Старая Бинарадка, 2019]. Термин сабан в значении 'плуг' заимствован в старобинарадский говор из тюркских языков. В мокша-мордовских говорах данное заимствование встречается нечасто, плуг же обозначается, как правило, лексемой керяз. Отметим, что сравнительно большое число заимствований из тюркских языков характерно для мокша-мордовских говоров Самарской Луки, в том числе для бахиловского [4].

Географический термин поле в составе данного названия заимствован из русского языка. Тенденция к замене в топонимии мордовского термина пакся на различного рода заимствования из русского языка прослеживается как в мокшанских, так и в эрзянских говорах региона.

\section{Турбане}

Название одного из полей в окрестностях Старой Бинарадки. Еще одно название-метафора для полей в рассматриваемом топонимическом пространстве, данное по форме поля: турба - адаптированная в мокша-мордовской этноязыковой среде русская лексема труба + -не - аффикс уменьшительности в мордовских языках (мокша-мордовская литературно-письменная форма данного аффикса имеет вид -ня, но в старобинарадском говоре он принял форму -не) = 'трубочка'. В мордовской топонимии часто встречаются названия полей, обусловленные их характерной формой, например в окрестностях райцентра Шентала Самарской области нами отмечено Пистолет пакся - поле, название которого буквально переводится на русский язык как 'Пистолетполе' [ПМА, Самарская область, Шенталинский район, Старая Шентала, 2019].

\section{Улашкань дол}

Топоним относится к одному из оврагов в окрестностях села. По словам информантов, происхождение данного названия неизвестно. Отметим, что основной 
ареал топонимов с географическим термином дол располагается по другую сторону Старобинарадского бора, у с. Молгачи, а в топонимическом пространстве Старой Бинарадки данный географический термин применяется лишь к определенному типу оврагов с пологими склонами. Первая составляющая названия однозначно не этимологизируется. Можно предложить следующее этимологическое решение: алаша 'лошадь' + -ке - один из аффиксов уменьшительности в мордовских языках + -нь - аффикс принадлежности в мордовских языках = 'лошадкин дол'. Ввиду отсутствия дополнительных аргументов этимология остается гипотетической.

\section{Шей грай}

Название одного из озер в окрестностях Старой Бинарадки. Со слов информантов: «Там озеро или пруд... камышом заросло все» [ПМА, Самарская область, Красноярский район, Старая Бинарадка, 2019]. Лексема шяй/ шей в мокша-мордовских говорах Самарского Поволжья имеет значения 'осока', 'камыш', 'трава на болоте'; значение 'болото' для нее во всех без исключения говорах региона утрачено. Лексема грай как в мокша-мордовских, так и в эрзя-мордовских говорах Самарского Поволжья довольно широко представлена, в том числе в топонимии, и является фонетической адаптацией русской лексемы край. Одно из распространенных значений данной лексемы в мордовских говорах региона - 'берег'. Особенно важно в контексте происхождения мордовского населения Старой Бинарадки то, что в мокша-мордовских говорах Самарской Луки она также отмечена в составе географических названий: Рав грай - участок берега Волги в окрестностях с. Шелехметь [ПМА, Самарская область, Волжский район, Шелехметь, 2018]. Учитывая сведения, полученные от информантов, и значения слагающих топоним лексем, значение лимнонима следующее: шей 'осока; камыш' + грай 'край; берег' = 'камышовый берег'.

\section{Эрьхкеняса}

Название одного из озер в окрестностях Старой
Бинарадки. Объяснение топонима и характеристика объекта номинации со слов информантов: «Эрьхкеняса - это озерцо такое, лесное озеро. Там даже купаться можно, песочек с одной стороны» [ПМА, Самарская область, Красноярский район, Старая Бинарадка, 2019]. С мокша-мордовского языка на русский язык топоним переводится следующим образом: эрьхке 'озеро' + -ня/-не - аффикс уменьшительности в мордовских языках + са - местная вариация мордовского аффикса определенности -сb = 'озерцо'. Аффикс определенности в данном случае указывает на то, что слово Эрьхкеня является именем собственным. Также надо отметить, что в мокша-мордовском языке данный аффикс может использоваться и в таких случаях, когда определенность того или иного объекта трудно поставить под сомнение, например: Шись 'Солнце', Мокшесь 'река Мокша' и т.д.

\section{Зак^ючение}

Анализ топонимической номенклатуры мокша-мордовского села Старая Бинарадка и его окрестностей позволяет отметить следующее. В топонимической номенклатуре исследуемой территории прослеживается заметное влияние характеристических особенностей старобинарадского говора мокша-мордовского языка. Географическая лексика, бытующая в старобинарадском говоре, получила значительное отражение в топонимии Старой Бинарадки и ее окрестностей. Существенная часть географической терминологии старобинарадского говора имеет надежные параллели в географической лексике мокшанских говоров Самарской Луки. В топонимической номенклатуре Старой Бинарадки нашли отражение этноязыковые, хозяйственно-бытовые и культурно-религиозные аспекты заволжского этапа истории бинарадской мордвы. Одной из отличительных черт исследуемого топонимического пространства является отсутствие в нем топонимического субстрата - этот факт может свидетельствовать о том, что мордва при освоении данной территории не застала здесь предшествующих насельников.

\section{ЛИТЕРАТУРА}

1. Барашков В.Ф. Названия рек Ульяновско-Самарского Поволжья. Ульяновск: УГПИ, 1991.

2. Барашков В.Ф., Дубман Э.Л., Смирнов Ю.Н. Самарская топонимика. Самара: СамГУ, 1996.

3. Беленов Н.В. Географическая топонимная лексика мокша-мордовского населения с. Старая Бинарадка Самарской области // Ежегодник финно-угорских исследований. 2019. №4. С. 550 - 558.

4. Беленов Н.В. Топонимическое пространство мокша-мордовского села Бахилово на Самарской Луке // Ономастика Поволжья. Великий Новгород, 2019. C. $169-173$

5. Вершинин В.И. Этимологический словарь мордовских языков. Йошкар-0ла, 2005.

6. Гераклитов А.А. Роль Саратова и Самары XVII В. в жизни мордвы // Известия Нижневолжского института краеведения. Саратов, 1929. С. 3 - 12.

7. Гребнева А.М., Казаева Н.В., Натуральнова Г.А. Пространственная лексика и её роль в формировании мордовской топонимической системы // Ежегодник финно-угорских исследований. 2019. Т.13. №4. С. $559-567$.

8. Иванова Г.С. Сайгутина К.И., Дивеев А.В. Топонимы села Мордовские Парки: этимология и структура // XLVIII Огарёвские чтения. Саранск: Изд-во Морд. 
гос. ун-та, 2020. С. $20-25$.

9. Инжеватов И.К. Топонимический словарь Мордовской АССР: Названия населённых пунктов. Саранск: Мордовское книжное издательство, 1987.

10. Керт Г.М. Саамская топонимная лексика. Петрозаводск: КЦ РАН, 2009.

11. Кляшторный С.Г., Султанов Т.И. Государства и народы Евразийских степей: от древности к Новому времени. СПб.: Петербургское востоковедение, 2009.

12. Кузнецов С.К. Русская историческая география. Мордва. М.: Синодальная типография, 1912.

13. Магницкий В.К. Чувашские языческие имена. Казань: Типография Императорского Университета, 1905.

14. Мельников-Печерский П.И. Очерки мордвы. Саранск: Мордовское книжное издательство, 1981.

15. Натуральнова Г.А. Фонетические особенности русских заимствований в шокшанском диалекте эрзянского языка (на материале шокшанских говоров Теньгушевского района) // Финно-угорский мир. 2015. №2. С. 38 - 45

16. Перетяткович Г.И. Поволжье в XVII и начале XVIII века (очерки из истории колонизации края). Одесса: Типография П.А. Зеленаго, 1882.

17. Попов А.И. К вопросу о мордовской топонимике // Филологические доклады. Саранск, 1948. Т.2. С. 203 - 230.

18. Феоктистов А.П. Очерки по истории формирования мордовских письменно-литературных языков. Саранск: Мордовское книжное издательство, 2008.

19. Цыганкин Д.В. Ойконимия мордовского Заволжья // Ежегодник финно-угорских исследований. 2010. №3. С. 9 - 14.

20. Цыганкин Д.В. Память, запечатлённая в слове: словарь географических названий Республики Мордовия. Саранск: Красная Октябрь, 2005.

21. Paasonen H. Mordwinische Worterbuch. Helsinki: Societe Finno-Ougrienne, 1990 - 1996.

22. Witsen N. Noord en oost Tartarie. Deel 2. Amsterdam, 1692.

(с Беленов Николай Валерьевич (belenov82@gmail.com).

Журнал «Современная наука: актуальные проблемы теории и практики»

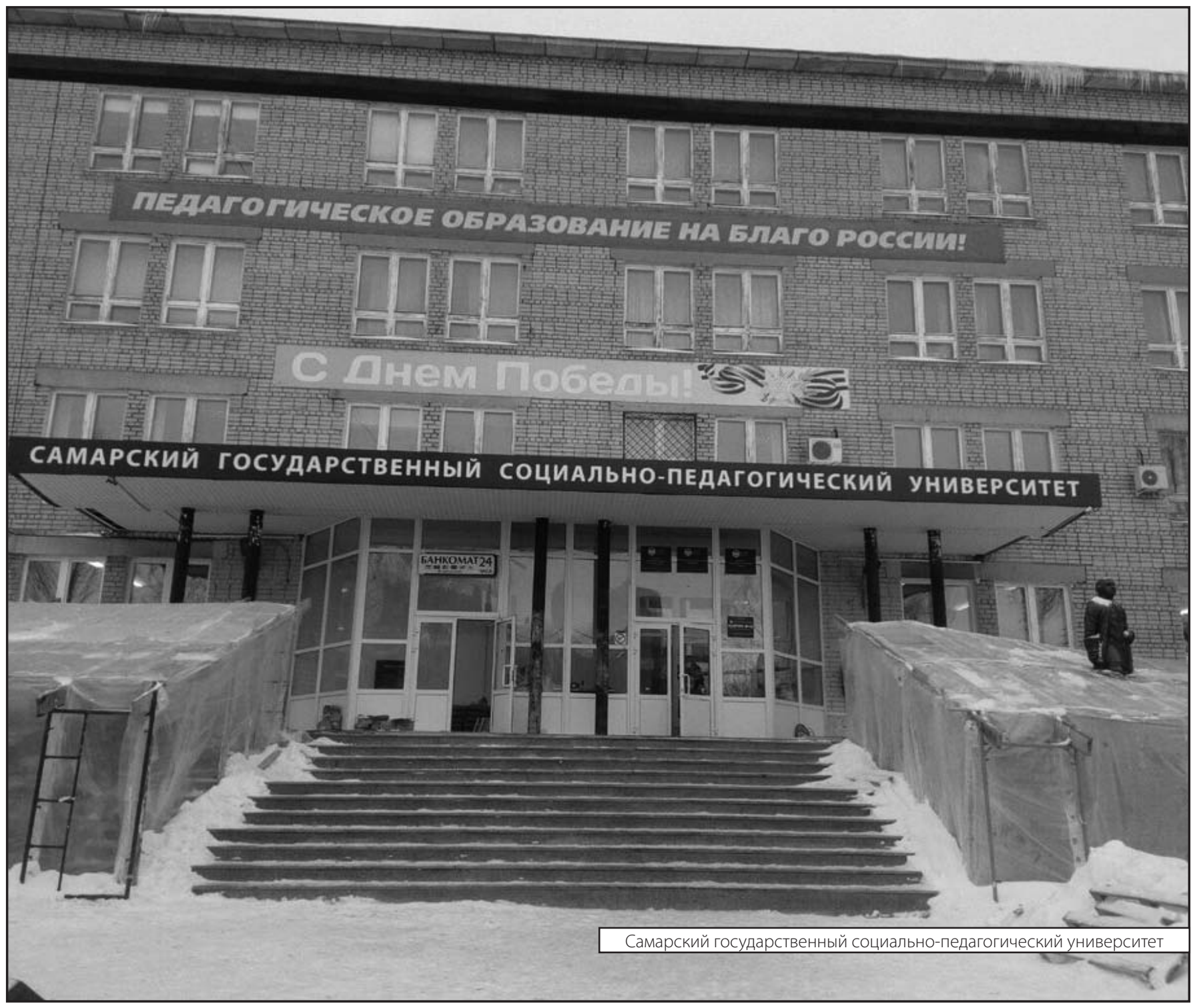

